\title{
Impact of inhaler use on dental caries in asthma pediatrics patients: A case-control study
}

\author{
Victor Chumpitaz-Cerrate, PhD. ${ }^{a}$, José A. Bellido-Meza, DDS ${ }^{b}$, \\ Lesly Chávez-Rimache, DDSc and Cecilia Rodríguez-Vargas, Magister ${ }^{d}$
}

\begin{abstract}
Introduction. Asthma is a chronic inflammatory disease that is highly prevalent among pediatric patients. The results about the effect of asthma on the rate of dental caries are contradictory. The objective of this study was to determine the prevalence of dental caries in asthma pediatric patients using inhaled drugs.

Population and methods. Case-control study in a sample made up of pediatric patients who attended Centro Médico Naval "Cirujano Mayor Santiago Távara" between December 2014 and March 2015. Patients were divided into two groups: group A (cases)included asthma patients using inhalers as part of their treatment; group B (controls), healthy subjects who attended the same facility. A medical examination was done to determine the type, time, and frequency of treatment and an oral exam, to establish the prevalence of dental caries and the decayed, missing, and filled teeth (DMFT) index.
\end{abstract}

a. School of Health Sciences, Laboratory of Pharmacology, Universidad Científica del Sur. Lima, Peru.

b. Dental Surgeon, private practice.

c. School of Dentistry, Laboratory of Pharmacology, Universidad Nacional Mayor de San Marcos. Lima, Peru.

d. School of Dentistry, specialist in Statistics and Research, Universidad Nacional Mayor de San Marcos. Lima, Peru.

E-mail address:

Victor Chumpitaz-

Cerrate, PhD.:

vchumpitaz@cientifica. edu.pe

Funding:

None.

\section{Conflict of interest:}

None.

Received: 12-4-2018

Accepted: 6-6-2019

\section{INTRODUCTION}

Dental caries is one of the most prevalent infectious diseases in the pediatric population. According to the World Health Organization (WHO), dental caries is the most common disease in some Asian and Latin American countries, affecting 60-90\% of schoolchildren. In addition, $90 \%$ of schoolchildren aged 5-17 years in America have dental caries. ${ }^{1-3}$

Bronchial asthma is considered a chronic inflammatory airway disorder that mostly affects pediatric patients, up to $10-15 \%$ of males and $7-10 \%$ of females. ${ }^{4,5}$ It is known that asthma may lead to a higher prevalence of dental caries due to different biological mechanisms, such as direct changes in salivary composition or indirect changes caused by inhaled bronchodilator use (beta 2 adrenergic agonists, anticholinergics, and other similar acting agents). The administration of inhaled drugs alters saliva quality and quantity. A reduction in saliva causes an increase in oral microbiota, especially the cariogenic microbiota. In addition, many inhaled drugs have sugar as an excipient, which serves as a substrate for cariogenic bacteria and alters the oral $\mathrm{pH} \cdot{ }^{4-7}$ Beta 2 agonists activate beta ${ }_{2}$ receptors in the salivary glands, thus promoting cyclic adenosine monophosphate (cAMP) production, which reduces salivary secretion and protein synthesis. In addition, only 10-20\% of these drugs reach the lower airways; the rest remain at the oropharynx and upper airways level, so they serve as a substrate for cariogenic bacteria and alter the oral $\mathrm{pH},{ }^{3,4,7-10}$

Different investigations have suggested that inhaler use may be 
responsible for the higher prevalence of dental caries in asthma patients.,11 Conversely, some studies have mentioned that there is no direct causal relationship between inhaler use and a higher prevalence of dental caries in asthma patients, compared to healthy subjects. ${ }^{12,13}$

Understanding the impact of bronchial asthma on oral health would help to provide comprehensive dental care and establish public health strategies aimed at prevention.

Therefore, the study hypothesis was that using inhaled bronchodilators and/or corticosteroids increased the prevalence of dental caries in asthma pediatric patients.

The objective of this study was to determine the prevalence of dental caries in asthma pediatric patients using inhaled drugs.

\section{POPULATION AND METHODS}

This was an observational, descriptive, casecontrol study. It included pediatric patients aged 3-13 years that attended the outpatient offices of the Department of Pediatric Pulmonology and the Department of Pediatric Dentistry of Centro Médico Naval (CEMENA) between December 2014 and March 2015.

\section{Selection criteria}

Patients who were on active treatment with inhaled drugs (budesonide/salbutamol or fluticasone/salmeterol) for more than a year, who had been diagnosed by a pediatric pulmonologist, and who attended the facility with another pediatric patient who was systemically healthy were selected. In addition, in their dental examination, they showed a good or fair oral hygiene index ( $\mathrm{O}^{\prime}$ Leary) and cariogenic diet. The O'Leary index was determined using plaque disclosing tablets, which stain the teeth that have dental plaque. Each stained tooth was added and the sum was divided by the total teeth. The index was classified into good (<20\%), fair (20-49\%) or poor $(>49 \%)$. The cariogenic diet was based on sugar intake during the week and classified into good (0-2), fair $(3 / 4)$ or poor $(>4)$.

Pediatric patients wearing braces or who had a comorbidity that may have significantly affected their oral health or who were receiving mid- or long-term antibiotic therapy were excluded.

Based on inclusion criteria, group A (cases) was made up of asthma pediatric patients who were on active treatment with inhaled drugs. In all cases, patients received inhalation therapy with aerochamber. Group B (controls) was made up of systemically healthy pediatric subjects who accompanied asthma patients to their outpatient visit to the Department of Pediatric Pulmonology. All participants were paired by age, sex, family history, and socioeconomic level. The assessment of the oral hygiene index and cariogenic diet was carried out at the Department of Pediatric Dentistry on the same day of the visit to the Department of Pediatric Pulmonology.

\section{Protocol}

The informed consent and assent were delivered to each participant and their caregivers, and the study conditions were explained to them. Patients were selected based on inclusion criteria; then, data were collected by the investigator with the support of the pediatric pulmonologist.

The assessment included a medical examination by the pediatric pulmonologist based on the patient's medical records, including the type of inhaled drug used (bronchodilator and/ or corticosteroid), the frequency of use (average number of puffs per day), and total treatment duration (considering drug withdrawal periods).

The investigator performed a clinical dental assessment in both groups at the Department of Pediatric Dentistry based on the presence of dental caries and the decayed, missing, and filled teeth (DMFT) index. Dental examinations were done in accordance with the WHO guidelines. ${ }^{15}$ In addition, caregivers were informed of the oral health status of patients and the potential impact of inhalers on dental caries based on the history mentioned above.

Bioethical considerations: The study protocol was approved by CEMENA's Research Ethics Committee. The informed consent and assent were designed in accordance with the ethical principles of the Declaration of Helsinki. ${ }^{14}$

\section{Analysis of results}

The statistical software package used was SPSS, version 22.0. Qualitative outcome measures were analyzed using a $\chi^{2}$ test for inferential statistics. The relation among quantitative outcome measures was established using the Mann-Whitney U test and the Kruskal-Wallis test. Besides, the effect of outcome measures on the DMFT index was assessed based on a multiple linear regression. Data were described as mean \pm standard deviation with a $95 \%$ confidence interval (CI) for all statistical tests.

The sample size $(n=92)$ was estimated considering a $95 \%$ confidence level $(p=1.96)$ 
for an estimated proportion of the population with dental caries of $71.4 \%$ and an accuracy or maximum error of $5 \% .^{3}$

\section{RESULTS}

A total of 358 asthma pediatric patients attended the outpatient office between December 2014 and March 2015. Of them, 184 patients were selected based on inclusion criteria. Three patients did not agree to continue with the study because they were going to be transferred to a different hospital (2 in group A and 1 in group B). Finally, 184 participants were assessed; 92 in the case group and 92 in the control group. Participants' mean age was $8 \pm 4.45$ years; $48.9 \%(n=90)$ were males and $51.1 \%(\mathrm{n}=94)$, females.

The prevalence of dental caries was lower in the case group $(28.3 \%)$ compared to the control group (34.2\%); the difference was not significant $(p=0.094)$. The odds ratio (OR) was 1.67 with a $95 \%$ CI (0.91-3.05) (Table 1).

In relation to common inhaled drugs used by asthma patients, $87 \%$ of them $(\mathrm{n}=80)$ used budesonide/salbutamol; whereas $13 \%(\mathrm{n}=12)$ used the fluticasone/salmeterol combination.

Regarding treatment duration, it was observed that 12 asthma patients (13\%) had used inhalers for 1 to 2 years and their DMFT index was $1.91 \pm 2.74 ; 32$ asthma patients $(34.8 \%)$, for 2 to 4 years with a DMFT index of $3.46 \pm 2.88$; whereas 48 asthma patients (52.2\%), for more than 4 years, with a DMFT index of $4.27 \pm 3.09$. A direct significant relationship was observed between treatment duration with inhalers and the rate of dental caries $(p=0.04)$.

In relation to the frequency of inhaled drug administration, 80 asthma patients $(87 \%)$ used bronchodilators at a rate of 6 puffs per day, while $12(13 \%)$ required more than 6 puffs per day. Corticosteroids were used by 89 asthma patients $(96.7 \%)$ at a rate of 2 puffs per day, while $3(3.3 \%)$ required more than 2 puffs per day.

No significant differences were observed in relation to the DMFT index between the case and the control groups $(p=0.08)$. The DMFT index was $3.98 \pm 0.31$ in the case group and $4.73 \pm 0.32$ in the control group (Table 2).

The univariate linear regression analysis of the DMFT index showed that age and treatment duration were significant outcome measures, $p<0.05$. However, the multivariate linear regression analysis indicated that treatment

TABLE 1. Prevalence of dental caries by assessment group (N:184)

\begin{tabular}{|c|c|c|c|c|c|c|c|}
\hline & \multicolumn{4}{|c|}{ Assessment group } & \multicolumn{2}{|c|}{ Prevalence } & \multirow[t]{3}{*}{$P$} \\
\hline & \multicolumn{2}{|r|}{ Absence } & \multicolumn{2}{|c|}{ Presence } & & & \\
\hline & $\mathbf{N}$ & $\%$ & $\mathbf{N}$ & $\%$ & OR & $\mathrm{CI}$ & \\
\hline Cases & 40 & 21.7 & 52 & 28.3 & 1.67 & $(0.91-3.05)$ & $0.094^{*}$ \\
\hline Controls & 29 & 15.8 & 63 & 34.2 & & & \\
\hline Total & 69 & 37.5 & 115 & 62.5 & & & \\
\hline
\end{tabular}

Pearson's $\chi^{2}$ test $=2.80 ; \mathrm{p}=0.094$.

OR: odds ratio; CI: confidence interval.

TABLE 2. Decayed, missing, and filled teeth index by assessment group

\begin{tabular}{llccc}
\hline & Group & Mean & CI & $p$ value \\
\hline Decayed teeth & Cases & 1.72 & $1.24-2.20$ & 0.10 \\
& Control & 2.19 & $1.68-2.70$ & 0.55 \\
Missing teeth & Cases & 0.10 & $0.03-0.18$ & 0.06 \\
& Control & 0.14 & $0.03-0.24$ & 0.08 \\
Filled teeth & Cases & 1.84 & $1.39-2.30$ & $1.86-2.78$ \\
\multirow{2}{*}{ DMFT index } & Control & 2.32 & $3.05-4.31$ & $4.08-5.39$ \\
\end{tabular}

${ }^{*}$ Mann-Whitney U test $=3399.5 ; \mathrm{p}=0.087$.

CI: confidence interval; DMFT: decayed, missing, and filled teeth. 
duration was the only outcome measure that had a significant effect $(p=0.008)$ with a 1.33 regression coefficient (Tables 3 and 4 ).

\section{DISCUSSION}

This study did not find any significant evidence to consider that inhaler use by asthma pediatric patients would have an impact on dental caries. This is consistent with what has been reported by Godara et al., who established that the DMFT index of 100 asthma patients aged $10-45$ years who used inhalers was 1.76 and that of 100 healthy subjects, 1.46 . No significant differences were observed between both study groups. ${ }^{12}$

Likewise, Bahrololoomi et al., conducted a study in 92 children between 6 and 12 years old; the DMFT index of 46 asthma children was $5.25 \pm 2.25$ and that of 46 healthy children was $4.15 \pm 3.27$. No significant differences were observed between both groups. ${ }^{13}$

However, Arafa et al., found that the DMFT index in healthy children was $5.47 \pm 2.16$ and, in asthma children, $6.84 \pm 1.81(p=0.04){ }^{5}$ whereas Samec et al., observed that it was $1.69 \pm 2.63$ in healthy children and 7.01 \pm 5.59 in asthma patients $(p=0.01) .{ }^{11}$ Such differences may be because dental caries is a multifactorial infectious disease that depends on environmental, sociodemographic, behavioral, microbiological, and nutritional factors. ${ }^{16-19}$

Thomas et al. mentioned that the risk factors for dental caries in asthma pediatric patients using inhalers included a decrease in salivary flow caused by beta 2 agonists, increased lactobacilli and streptococci count, reduced salivary $\mathrm{pH}$, and the presence of fermentable carbohydrates. ${ }^{10}$

Sag et al., determined that two factors strongly related to dental caries were salivary flow and the dental plaque index, and reported that, after one month of treatment with a combination of a beta 2 agonist (salmeterol) and a corticosteroid (fluticasone), the rate of salivary secretion reduced significantly and the dental plaque index increased; this demonstrated that using beta 2 agonists significantly reduced salivary secretion and may increase the potential for dental caries. ${ }^{20}$

Ryberg et al., indicated that the total and parotid salivary secretion rates in asthma patients who used inhalers reduced by $26 \%$ and $36 \%$, respectively, compared to healthy subjects. ${ }^{21}$ In addition, the authors mentioned that using inhaled drugs in a preventive manner or for acute episodes altered the oral environment by reducing the salivary flow and $\mathrm{pH}$; such changes were related to dental caries and/or erosion, gingivitis, halitosis, xerostomia, and candidiasis. Other studies have reported similar findings. ${ }^{19,21-23}$

Alaki et al., revealed that the lactobacilli and streptococci count increased significantly with the combination of beta 2 agonists and corticosteroids in asthma patients after two years of treatment. This was because the long-term use of corticosteroids caused immunosuppression, resulting in a greater bacterial growth. ${ }^{24}$

For the purpose of assessing the association

TABLE 3. Univariate linear regression analysis for the decayed, missing, and filled teeth index by case and control group

\begin{tabular}{lcccc}
\hline \multicolumn{5}{c}{ Unstandardized } \\
\hline Outcome measure & B & Typical error & T & $p$ value \\
\hline Age & 0.483 & 0.049 & 9.869 & 0.000 \\
Frequency of bronchodilator use & 0.210 & 0.174 & 1.209 & 0.228 \\
Frequency of corticosteroid use & 0.209 & 0.169 & 1.23 & 0.219 \\
Treatment duration & 0.479 & 0.174 & 2.74 & 0.007 \\
\hline
\end{tabular}

TABLE 4. Multivariate linear regression analysis for the decayed, missing, and filled teeth index by case and control groups

\begin{tabular}{lcccc}
\hline \multicolumn{4}{c}{ Unstandardized } \\
\hline Outcome measure & B & Typical error & T & $p$ value \\
\hline Age & -0.082 & 0.09 & -0.90 & 0.365 \\
Frequency of bronchodilator use & -0.033 & 0.89 & -0.37 & 0.706 \\
Frequency of corticosteroid use & -0.23 & 0.99 & -0.23 & 0.814 \\
Treatment duration & 1.33 & 0.49 & 2.68 & 0.008 \\
Constant & 1.80 & 0.97 & 1.85 & 0.065 \\
\hline
\end{tabular}


between asthma and dental caries, different systematic reviews and meta-analyses have been carried out, including the one by Alavaikko et al., who did not find conclusive evidence to support such potential association. However, they suggested that asthma may double the risk for dental caries in primary and permanent dentition. 22

Different outcomes were reported in a recent review by Agostini et al., who found solid evidence of the association between asthma and the development of dental caries in primary and permanent dentition..$^{23}$

Shashikiran et al., assessed the severity of dental caries by comparing three treatments: inhaled salbutamol, inhaled beclometasone, and oral salbutamol for asthma children, and found that inhaled salbutamol was related to a significantly higher prevalence of dental caries compared to oral salbutamol and inhaled beclometasone. ${ }^{25}$

In addition, Chellaih et al., found that the prevalence of dental caries increased with the combined use of inhaled beta 2 agonists and corticosteroids. ${ }^{26}$

In this study, the DMFT index increased significantly in relation to inhaled treatment duration. Patients who received treatment for 1 to 2 years showed a significantly lower DMFT index than those treated for 2 to 4 years or for more than 4 years. Likewise, the multiple linear regression analysis of the effect of treatment duration on DMFT index showed a B value of $1.33(p=0.008)$; this meant that each year increase caused a 1.33 increase in the score units of the DMFT index.

This was consistent with the findings of Chellaih et al., who reported that asthma patients receiving inhaled corticosteroids for more than 2 years had 6 times more risks for dental caries compared to the control group (OR: 6.26). ${ }^{26}$ However, it disagreed with the findings of Boskabady et al., who conducted a study to assess whether inhaler use in asthma patients for 1 to 5 years, 6 to 10 years, 11 to 15 years, and more than 16 years affected the rate of dental caries. No direct significant relationship was observed between treatment duration with inhalers and the rate of dental caries. ${ }^{17}$

The role of asthma medications is probably a contributing factor; therefore, it is not surprising that, in some studies, they are associated with a higher prevalence of caries and that patients using inhalers (beta 2 agonists and / or corticosteroids) have a greater chance of developing dental caries compared to healthy controls.
However, in this study, no significant differences were observed in the prevalence of dental caries between asthma patients using inhalers and healthy subjects. It is important to recognize that dental caries is a multifactorial disease. It is recommended to conduct longitudinal studies that cover more years of follow-up as well as cohort studies to establish the causal relationship between inhaler use in asthma patients and dental caries considering other outcome measures, including salivary flow and $\mathrm{pH}$, and studies that implement a more detailed index to assess dental caries from baseline to establish a risk factor concept.

\section{CONCLUSIONS}

Inhaled drugs do not increase the prevalence of dental caries in asthma pediatric patients. However, there is a direct relationship between treatment duration and the prevalence of dental caries.

\section{REFERENCES}

1. Huartamendia R, Nappa A, Queirolo R. Problemas de salud bucal relacionados al uso de medicamentos por vía inhalatoria en trastornos respiratorios. Odontoestomatología. 2012; 14(20):4-16.

2. Gallegos López L, Martínez Pérez EM, Planells del Pozo $\mathrm{P}$, et al. Efecto de los medicamentos inhalados en la salud oral de los pacientes asmáticos. Odontol Pediatr (Madr). 2003; 11(3):102-10.

3. Echevarría LS, Herrera GO, Henríquez D’AE, Sepúlveda RR, et al. Prevalencia de caries temprana de la infancia en niños con enfermedades respiratorias crónicas. Rev Chil Pediatr. 2012; 83(6):563-9.

4. Bozejac BV, Stojšin I, Đuric M, Zvezdin B, et al. Impact of inhalation therapy on the incidence of carious lesions in patients with asthma and COPD. J Appl Oral Sci. 2017; 25(5):506-14.

5. Arafa A, AldahlawiS, Fathi A. Assessment of the oral health status of asthmatic children. Eur J Dent. 2017; 11(3):357-63.

6. Paganini M, Dezan CC, Bichaco TR, De Andrade FB, et al. Dental caries status and salivary properties of asthmatic children and adolescents. Int J Paediatr Dent. 2011;21(3):18591.

7. Busquets Monge R, Escríbano Montaner A, Fernández Benítez M, García-Marcos L, et al. Consenso sobre tratamiento del asma en Pediatría. An Pediatr. 2006; 64(4):365-78.

8. Mastora A, Vadiakas G, Agouropoulos A, GartaganiPanagiotopoulou P, et al. Developmental defects of enamel in first permanent molars associated with use of asthma drugs in preschool aged children: A retrospective casecontrol study. Eur Arch Paediatr Dent. 2017; 18(2):105-11.

9 .Choi H, Bae K-H, Lee JW. Association between age at asthma diagnosis and tooth loss. Acta Odontol Scand. 2018; 76(7):466-72.

10. Thomas MS, Parolia A, Kundabala M, Vikram M. Asthma and oral health: a review. Aust Dent J. 2010; 55(2):128-33.

11. Samec T, Amaechi BT, Battelino T, Krivec U, et al. Influence of anti-asthmatic medications on dental caries in children in Slovenia. Int J Paediatr Dent. 2013; 23(3):188-96. 
12. Godara N, Godara R, Khullar M. Impact of inhalation therapy on oral health. Lung India. 2011; 28(4):272-5.

13. Bahrololoomi Z, Bemanian MH, Ghaffourifard R, Ahmadi B. Effect of inhaled medication on dental caries index in asthmatic children. AllergolImmunopathol (Madr). 2018; 46(2):196-200.

14. Organización Mundial de la Salud. Encuestas de salud bucodental: métodos básicos. $4^{\mathrm{a}}$ ed. Ginebra: Organización Mundial de la Salud; 1997.

15. General Assembly of the World Medical Association. World Medical Association Declaration of Helsinki: ethical principles for medical research involving human subjects. J Am Coll Dent. 2014; 81(3):14-8.

16. Karova E, George C. Dental health in asthmatics treated with inhaled corticosteroids and long-acting sympathicomimetics. J IMAB. 2012; 18(2):172-9.

17. Boskabady M, Nematollahi H, Boskabady MH. Effect of Inhaled Medication and Inhalation Technique on Dental Caries in Asthmatic Patients. Iran Red Cres Med J. 2012;14(12):816-21.

18. Ayinampudi BK, Gannepalli A, Pacha VB, Kumar JV, et al. Association between oral manifestations and inhaler use in asthmatic and chronic obstructive pulmonary disease patients. J Dr NTR Univ Health Sci. 2016; 5(1):17-23.

19. Heidari A, Seraj B, Shahrabi M, Maghsoodi H, et al. Relationship Between Different Types and Forms of AntiAsthmatic Medications and Dental Caries in Three to 12 Year Olds. J Dent (Tehran). 2016; 13(4):238-43.
20. Sag C, Ozden FO, Acikgoz G, Anlar FY. The effects of combination treatment with a long-acting beta2-agonist and a corticosteroid on salivary flow rate, secretory immunoglobulin $\mathrm{A}$, and oral health in children and adolescents with moderate asthma: a 1-month, single-blind clinical study. Clin Ther. 2007; 29(10):2236-42.

21. Ryberg M, Moller C, Ericson T. Saliva composition and caries development in asthmatic patients treated with beta 2-adrenoceptor agonists: a 4-year follow-up study. Scand J Dent Res. 1991; 99(2):212-8.

22. AlavaikkoS, Jaakkola M, Tjäderhane L, Jaakkola JJ. Asthma and caries: a systematic review and meta-analysis. Am J Epidemiol. 2011; 174(6):631-41.

23. Agostini BA, Collares KF, Costa FDS, Correa MB, et al. The role of asthma in caries occurrence - meta-analysis and meta-regression. J Asthma. 2018; 23(2):1-12.

24. Alaki SM, Ashiry EA, Bakry NS, Baghlaf KK, et al. The effects of asthma and asthma medication on dental caries and salivary characteristics in children. Oral Health Prev Dent. 2013; 11(2):113-20.

25. Shashikiran ND, Reddy VVS, Raju PK. Effect of antiasthmatic medication on dental disease: dental caries and periodontal disease. J Indian Soc Pedod Prev Dent. 2007; 25(2):65-8.

26. Chellaih P, Sivadas G, Chintu S, VaishnaviVedam VK, et al. Effect of anti-asthmatic drugs on dental health: A comparative study. J Pharm Bioallied Sci. 2016; 8(Suppl 1):S71-80. 